\title{
Insurability Issues Associated with Managing Existing Hazardous Waste Facilities
}

\author{
by Dr. Baruch Berliner and Juerg Spuehler*
}

\section{EXECUTIVE SUMMARY}

\section{The basic situation}

After introducing criteria of insurability and other tools for an insurability analysis of risks in general, endogenous and exogenous components of hazardous waste risks which impede insurability are examined. The analysis pinpoints properties of hazardous waste risks and the social and legal environment that have driven these risks out of the domain of subjective insurability for may professional risk carriers. By doing so, the analysis not only uncovers what has been done wrongly but also how it could have been done better and how it should be done better in future to make lost insurance capacity available again for at least part of the hazardous waste risks.

\section{European insurance set-ups}

In Europe, various specific schemes are in operation to cover pollution risks: the GARPOL in France, the Italian Pool Inquinamento, and the MAS-Pool in the Netherlands; in Sweden, the existing concept of EIL covers is to be supplemented by a public fund or an equivalent insurance scheme (both of compulsory nature). All these approaches avoid the conflict between sudden/accidental and gradual, and abstain from applying the named perils concept. However, most of them offer rather limited financial cover, all do not consider the consequences of the accumulation of legally allowed polluting activities and those of unlawful behavior in a clear way, and all leave restoration and cleanup costs outside the scope of cover.

\section{The consequences}

The question arises whether a scheme based on tested principles of insurance coupled with untraditional elements could be established to meet the expectations of the facility operators, namely to finance at any time (by disregarding legal developments and terms possibly being subject to litigation) first party losses (restoration and clean-up costs) as well

\footnotetext{
* Swiss Reinsurance Company, Zurich.
} 
as third party injury and damage. If these expectations can be bridged with the general requirements of the insurance carriers (limitation of engagement in time and in amount), new frontiers would be set for hazardous waste facilities.

\section{Outline of a solution: The Liability Life Policy (LLP)}

A possible solution to the problem faced may be found in the LLP. The term "liability" signifies that it takes care of liabilities of any kind imposed on the facility operator, the term "life" demonstrates that the whole life-span of the facility is focused on, and the term "policy" is applied as the risk is insurance-like transferred to a traditional insurer. The LLP takes care of the first and third party losses during the whole active and passive life-span of the facility. It is financed by an initial pay-down sum (as part of the whole investment for a waste site) and by periodical contributions incorporating incentives to the site operator to outlay and to run the facility as safely as possible.

The risk carrier guarantees as from inception of the scheme a prefixed maximum amount for balancing out the possible losses falling on the facility operator. At any time gaps may arise between the accrued fund and the amount due for losses occurred. The contingent amount resulting therefrom constitutes the risk element to be borne by the risk carrier. His obligations also extend to assessing the facility, to servicing and supervising it, to rendering technical support, to handling and adjusting the claims and to investing the funds accruing in the course of time. 